
\title{
Systems
}

\section{A Brief Review of Electrospinning of Polymer Nanofibers: History and Main Applications}

\author{
Riffat Amna ${ }^{1}$, Kabbir Ali ${ }^{2, *}$, Muhammad Irfan Malik ${ }^{3}$ and Sami Ibn Shamsah ${ }^{4}$ \\ ${ }^{1}$ Department of Chemical Engineering, Khalifa University, Abu Dhabi, United Arab Emirates \\ ${ }^{2}$ Department of Mechanical Design Engineering, Chonnam National University, Yeosu 550-749, South Korea \\ ${ }^{3}$ Department of Chemical Engineering, College of Engineering, University of Hafr Al Batin, Hafr Al Batin, Saudi Arabia \\ ${ }^{4}$ Department of Mechanical Engineering, College of Engineering, University of Hafr Al Batin, Hafr Al Batin, Saudi Arabia
}

Corresponding Author Email: ali_kabbir@hotmail.com

\begin{abstract}
Electrospinning is an intensely facile methodology for the precise manufacturing of polymer nanofibers by manipulation of electrostatic force, which stunts like a driving force. In this technique, fibers produced with a diameter range between 50 to $500 \mathrm{~nm}$. Two practices are made up by the scientists for electrospinning of versatile polymer. Polymers can be electrospun into ultrafine fibers in solvent solution or melt form. Tremendous progress had been made in this field in the past, and numerous applications were inaugurated. It's a field of nanotechnology which rapidly growing due to enormous potential in creating novel applications regarding morphologies, materials structure, surface area, porosity, and Reinforcement in nanocomposite development. Fibers can be assembled in the form of nonwoven, aligned, patterned, random three-dimensional structures and sub-micron fibers. Many complications faced during electrospinning, for example, control the morphology and structure of Nanofibers, analyze surface functionality, and assembling strategies for various polymers. We need to find out various parameters for accurate fiber assembly. Here we briefly review the evolution activities in the field of electrospinning, understand its process, polymeric structure, property characterization, technology frailty, research provocations, future expectations, and resourceful applications.
\end{abstract}

Keywords: electrospinning, taylor cone, electrical jet trajectory, ultrafine fibers, electrostatic force, fiber assembly, sub-micron fibers Received: June-05-2020, Accepted: July-09-2020, https://doi.org/10.14447/jnmes.v23i3.a01

\section{INTRODUCTION}

Polymeric nanofiber production through electrospinning is one of the most eye-catching applications of the electrospun methodology. It has broader applications in the field of science and technology. At the beginning of this era, all researchers have focused on the nanofiber production process; actually, the concept of electrospinning was introduced by English physicist William Gilbert in the 15th century. The word of electrospinning is derived from "electrostatic spinning" [1-5]. William Gilbert produces the electrostatic attraction between liquids by preparing an experimental setup in which he observed that in start, water droplets are spherical at the dry surface of the substrate [6]. But they converted into a cone shape when electrostatic force was applied to them. Later on, this cone shape is known as Taylor cone. The first modern electrospinning patent was filed by American inventor John Francis Cooley in 1900 [7], and the first attempt to establish an experimental procedure was made by Anton Formhals between 1934 and 1944 [8]. The first polymer solution utilized for the electrospinning process is cellulose acetate. Anton introduced the polymer solution between two electrodes, which are oppositely charged. One electrode was placed on to the collector and another one in solution. For solution ejection, a metal spinneret with a small hole was utilized.

This process able to produce continuous fibers on a large scale. Nanofibers have a vast surface area to volume ratio, which is a thousand times larger than the human hair. When diameter shrunk from micrometer to submicron, then it exhibits incredible characteristics and become $10^{\wedge} 3$ times larger than microfiber [9]. Moreover, it shows flexibility in surface functionalities and excellent mechanical properties like stiffness and tensile strength. These outstanding properties nominated the polymer nanofibers as an appropriate candidate for versatile applications.

Electrospinning has enormous potential to improve current technology by finding unique applications significantly. In the past, polymeric fibers were produced by conventional methods like phase separation, template synthesis, self-assembly, and drawing, which produce the fibers with the diameter in the range of micrometers [8].

In the drawing process, only viscoelastic materials suffer substantial deformation. Due to their cohesive properties, they support stress developed during pulling and produce long fibers one by one and have similarities with dry spinning [10]. When we take a look at template synthesis, mostly electronically conducting polymers, carbons, semiconductors, and metals are fabricated. A Nanoporous membrane used as a template for the production of solid or hollow shape nanofibers and cannot be able to make one by one continuous fiber [11, 12]. Individual and pre-existing components organize themselves in self-assembly according to their desired shape and function [13, 14]. But it takes too much time for continuous fiber production, just like the phase separation process. Because in phase separation, dissolution, drying, freezing, gelation, and extraction are involved in the formation 
of nanoscale porous foam [15]. After taking a short review of some past technologies, we have come to know that at the industrial level for the production of large nanoscale fibers, electrospinning is the only best technique for one by one continuous fiber from various polymers [16, 17]. In conventional techniques, fibers were produced by using gravitational, rheological, inertial, aerodynamic, and tensile forces.

At the laboratory level, for the electrospinning process, the experimental assembly is effortless. We need a syringe, needle with a flat tip, high voltage power supply, back pump for adjusting collective distance, and a conducting surface. In the electrospinning process, fiber can produce with the diameter range in ultrafine nanometers by the utilization of tensile forces created in the axial direction of polymer solution with the help of induced charges in the presence of electrostatic forces. Electrostatic forces of attractions are utilized in this process to establish a well-balanced surface tension on the substrate. If the surface tension is completely balanced, then there is very smooth fiber production. Otherwise, we can observe the bead formation [18]. Due to an increase in charge repulsion against the surface tension, a Tylor cone is generated. The electric potential is applied between the droplets of the solution and a targeted substrate surface. This process utilizes high voltage for the ejection of charged jets from polymer melts or solutions through a spinneret. Routes of jets are controlled by an applied electric field. Sometimes jet exhibits bending instabilities due to some repulsion forces between charge carrier particles. Jets extend through spiraling loops when the loop increases in diameter, then the size of the jet also increases, and it becomes thinner [19].

Produced fibers are highly charged, and they are oppositely directed towards the collector. The collector may be in the shape of a rotating drum or flat surface covered with aluminum foil. From this Taylor cone solution in the form of charged particles come out with a specific trajectory. After solvent evaporation, it is observed a polymeric fiber on the surface of the substrate [20-26].

While dealing with this process, it should have to control some critical parameters, which were characterized as systematic and process parameters. In systematic parameters, it includes the viscosity of the polymeric solution, applied voltage, conductivity, dielectric constant, molecular weight distribution of the polymer, hydrostatic pressure in capillary action, charges carried by jet, and surface tension. For example, the potential difference is depended on the properties of the spinning solution, its molecular weight, and viscosity [27-29]. Hence, all these parameters are interlinked with each other. By varying these parameters, it can be introduced versatile types of polymeric nanofiber applications like multifunctional separation membranes, wound dressing material, tissue engineering, drug delivery, artificial blood vessels, nanocomposites, non-woven fabrics, Nanocatalysis, filtration, and optical electronics and many others. It can also align nanofibers with the unique form of nanotubes and nanowires.

Process parameters are concerned with the preparation process of the polymer solution. During polymeric solution preparation, temperature, humidity, porosity, an electric potential at the tip of a needle, collective distance, concentration, motion of targeted substrate, and sensitivity of all materials have been carefully considered [27-29]. For example, if Azobisisobutyronitrile is using in the case of the molecularly imprinted polymer solution. Due to light-sensitive material, AIBN should have to cover with wire or bottle in which we place our solution so that it not be affected by light. Collective distance is critical during fiber production. If we decrease the distance, then fibers stick to each other. So we must try again and again to find an appropriate value for all parameters.

A polymer solution must have an appropriate concentration of fiber production. If it is viscous, then polymer motion through electric jet becomes a difficult task, and it generates beads due to low surface tension. Mostly we don't want beads formation; we only concerned with thin fiber production. On the other hand, if a solution is less viscous, then ultimately, it is not exhibit electrospinning. Most probably, it shows electrospraying in the form of big droplets. In the case of electrospinning or electrospraying, we can analyze the situation by seeing the shape of the Taylor cone. If it is electrospraying, then big droplets are sprinkling on the collector. Or if there is an electrospinning process, then first a pendant drop of polymer solution charged, then expand and at the last show a Taylor cone.

So for perfect thin fiber production, we need an appropriate polymer concentration, well-balanced surface tension, and charge density. All these parameters help in preventing the jet from collapsing into droplets before solvent evaporation. We don't have some literature or exact values for the electrospinning process of any component. It depends on practice and varies case by case. For example, in the case of PMMA with DMF solvent, a perfect fiber makes when the concentration of fiber is between 20 to $30 \mathrm{wt} \%$ with $15 \mathrm{KV}$ and $18 \mathrm{~cm}$ collective distance [30].

Due to the flexible nature of this process, electrospinning can be able to fabricate continuous nanofibers from a variety of materials. Morphological changes can be created in polymer melts while electrospinning by decreasing distance between needle and substrate, decreasing electric field, and concentration of polymer in solution. Current research characterizes many electro-spinnable materials. Like we can produce nanofibers with electrospinning from polymers, composites, semiconductors, and ceramics [27, 28, 31-37]. But the most common electrospun material is a polymer with a vast range of applications. Electrospun polymeric nanofibers possess a high surface area to volume ratio with extended length to diameter ratio, flexibility in surface functionalities, excellent mechanical properties, and lowest porosity.

It is necessary to fabricate various assemblies because of fiber arrangements and morphology effect vigorously to realize the potential of electrospun fibers. Due to the size of nanofibers, it's hard to produce versatile assemblies through physical manipulation, that's why this technique has a significant edge in the case of large-scale nanofiber production. Apart from different morphological assemblies of polymer, there are also many applications associated with the versatile shape of thin fibers through electrospinning. By adjusting the polymer concentration, charge density, collective distance, and polymeric flow rate, we can introduce many different shapes of thin polymers. Like branched fibers, flat ribbons, ribbons with other shapes, and longitudinally splitable long fibers are mostly observed [38, 39]. Electrospinning is widely used for different types of polymers like polyolefin, polyamides, polyester, aramid, and acrylic. And in biopolymers like proteins, DNA, polypeptides, and photonic peptides [8].

Now we are aware of many applications of electrospinning, and its process also looks quite simple. Most of the relevant data to this technique were found in the Science finder Scholar 
search system. This data show clearly that in the past few years, electrospinning gets too much attention. Many experiments were done with this technique by using different polymers. According to one estimation, more than 100 polymers were electrospun successfully by this technology. But, at the start, researchers faced many problems on different issues such as to set exact process conditions for different applications, voltage range, collective distance, fiber diameter, and, most importantly, its characterization through scanning electron microscopy. To establish the fundamentals of this technique, and to know the array of nanofibers, scientists focused on nanofibers assembly, modifications in the experimental set-up, try various electrospinning designs and different values of parameters. Here we generalize the efforts done to establish modern electrospinning technology. Although this technique is now very developed, still its understanding is quite limited. A systematic review has been made in this paper to understand research and development regarding electrospinning, including history, old fiber production techniques, processing, and effect of various parameters, applications, and fiber characterization.

\section{HISTORY}

The concept of electrospinning was introduced by William Gilbert in 1600 when he described the deformation of water droplets by static electricity [6]. It gained significant importance at the commercial level in the 1990s, and it has also rooted in the invention of aerosol spray. In 1745 Bose applied a high electric potential to liquid droplets [40]. Lord Rayleigh investigated how to overcome the surface tension of droplets by electric charges [41]. Electrodynamics was widely used to explain the idea of excitation of dielectric liquids under the influence of electric charges by Larmor 1898 [42]. The first effort to produce fibers through electrospinning was made by Cooley and Morton in 1900 [7]. Cooley patented a set-up in which electrodes are used to direct the electrospinning jet. In 1917, Zeleny photographed the electrospinning process [43]. Early scientists did a lot of work-related to design the experimental procedure. In 1929, Hagiwaba did the fabrication of artificial silk by using electrical charges [44]. The first successful attempt to establish an experimental procedure was made by Anton Formhals between 1934 and 1944 without the use of spinneret. In this process, there was a moveable collector for threads in stretched situations. These threads were parallel aligned. For the first time, this process was observed during the electrospinning of cellulose acetate fibers using acetone as the solvent [8, 45]. Formhals faced many difficulties while producing fibers through spinning. He faced the biggest problem with the complete drying of fibers because there is a very short distance between spinning and collecting devices. Later on, he increased the distance, which increased the drying time for fibers [2]. He also introduced many other methods for composite fiber production in 1940 [3].

After that, the scientist started to focus on the shape of the droplet coming out of the needle when an electric charge is applied. At that time still, the procedure was not utilized commercially. A scientist named Simons in 1966 patented the fibers with diameters of less than $1 \mathrm{~mm}$ [46]. Electrospun fibers were first commercialized for filter applications in the nonwovens industry [47]. In 1969 a scientist Taylor explained that the shape of droplets is conical, and later on, it was named as Taylor cone. To balance the surface tension of the polymer angle of the ejected jet should be 49.3 [48, 49]. Baumgarten, in 1971, reported the dependence of fiber diameter on the electric field and viscosity of the solution. He introduced microfibers with the range of diameter from 500 to $1000 \mathrm{~nm}$ [50]. The same effect was studied by Reneker et al. in the 1990s; they characterize polyethylene oxide (PEO) nanofibers by changing the applied voltage and solution concentration [51]. Reneker utilized high voltages up to $20 \mathrm{kV}$ to produce ultra-fine fibers, and it was the first time when electrospinning gained academic attention [19]. These produced PEO/Water fibers were further thinned by an extrusion process, which was proposed by Jaeger [52].

Since the 1980s electrospinning process had gained more attention due to ultrafine fibers production, the structure of fiber with the variable range of diameter. To study the relationship between temperature and diameter of fibers, in 1981, Larrondo and Mandley produced fibers from melt spinning and showed that with an increase of temperature and electric field, the diameter of fibers reduced [53-55]. With the time many technologies introduced to characterize the structural morphology of fibers like Transmission electron microscopy, scanning electron microscopy, x-ray diffraction, and differential scanning calorimetry. By utilizing all these technologies, in 1987, Hayati started to study beef aspects of electrospinning. The conclusion led to the conductivity of the liquid. It had shown that jets instability connected with highly conducting fluids at high voltages [56]. The first instability was introduced by Rayleigh in 1882, which is later on called Rayleigh's instability. It is axisymmetric. The electrospinning process suffers this kind of instability when the strength of the electric field or viscosity of the solution is very low [57]. Warner and Moses worked a lot on characterization and evaluation of fluid instabilities [58-60].

During fiber production, in most of the cases, bead formation was a big problem. Dietzel found the reason for bead formation. He showed that by increasing applied voltage, the shape of fibers changes, which originates from bead formation. Multiple field electrospinning was proposed to solve this problem [16, 57]. Shin also designed a new apparatus to improve the electrodynamics of the process by controlling experimental parameters [24]. Tsai and SchreuderGibson showed that nanofiber layers give less resistance to the moisture vapor diffusional transport [63, 64]. Spivak and Dzenis proposed that the Ostwalt- Dewaele power law could be applied to the electrospinning process [65]. In the start me 21 st-century people work a lot on nanofiber production and resolve many of its problems. Also, people started to introduce different applications of electrospun fibers. In 2003, Li et al. utilized the electrospinning process to fabricate the inorganic fibers. Uniaxially aligned nanofibers were prepared from ceramic and polymeric composites [66]. The first scientific journal on the continuous production of yarns from electrospun fibers was published in 2005, and its work credit goes to Smit et al. [67]. Then further, many scientists work on it and explore its more values. In 2006 Teo introduce 3D block electrospun nanofibers with the desired microstructure [68]. In 2011 Teo start work at the usage of 3D unique fibers, and he comes to know it's beneficial in bioengineering and clinical applications [69]. Tissue engineering is one of the best application [70]. Moreover, now, electrospun nanofibers are also utilized in the drug delivery system in vivo, especially for cancer treatment [71]. 


\section{PROCESS}

Electrospinning is a process that is used to produce nanofibers that have a small pore size and high surface area by applying high voltage. The electric source has a positive and negative polarity. The average diameter of electrospun fibers is between $100 \mathrm{~nm}$ to $500 \mathrm{~nm}$. Through this process, fiber production based on uniaxial stretching of the polymeric viscoelastic solution. Basically, in this process, we can take a polymer solution or melt for fiber production. Polymer solution or melt is injected into the plastic syringe and fit inside the machine. The electrospinning machine mainly consists of (a) collector, (b) needle pump, (c) electrode, and a high voltage power source. Before starting the experiments, first, we insert an Aluminum foil on the collector surface. A collector is a metal sheet or grid which is used to collect fibers. Sometimes we also use glass pieces to collect fibers and place glass on the Aluminum foil. It depends on the reaction conditions. The collector can be plate type or drum type. If its drum type, it looks like a rotating cylinder, and we do not use glass on them. We can cover its surface with Aluminum foil and tilt the capillary at a specific angle. Then we turn on the apparatus and set the flow conditions. Insert polymer solution containing syringe into the system. By moving the pump, we can adjust the position and collective distance. After that, apply a specific voltage to the needle for fiber production. Fibers are collected on aluminum foil or glass. We can use different types of polymer solutions for fiber production and depend upon their physical and chemical properties; for each solution, reaction conditions must be different. The same is the case with electrospinning machine assembly. We can assemble its main parts in different ways. We can also insert electrodes in the polymer fluid or placed at the tip of the capillary if we are using a metal needle syringe.

Setup for electrospinning is quite easy, but the mechanism is a little bit tedious. While producing nanofibers, bending instabilities cause complex electro-fluid-mechanical issues. During the spinning process, a syringe is fixed in the metering syringe pump. Polymer solution forced through this pump to form a pendant droplet at the tip of the syringe or capillary. The pump also sets the position and flow rate of the polymer solution. A charge is applied to the polymer solution inside the syringe with the help of the immersed electrode, and it induces free charges to the solution. The counter electrode is present at the collector, and charged ions move towards the opposite polarity and transfer the tensile forces to the solution. With the increase of electric charge, shear stress is created on the surface, which acts opposite side of surface tension, and droplets start repelling [72]. Hemispherical shape type pendant polymer droplets start to make a cone-like projection due to the electric field. Taylor cone form at this stage. When electric potential reaches towards its critical value, jet ejection starts [48], and electrified jet exhibit three different types of instabilities that influence the size and geometry of fibers. Most of the time, charge carriers have low mobility and take a very long time to move. After jet initiation, bending instabilities start. If the applied voltage value or viscosity of the polymer is very low, then mostly bead formation is observed. It is called Rayleigh instability [73, 74]. In bending, instability charge density is high, and there is a lot of charge repulsion. Whipping instability produces a bending force in the jet, and liquid starts to travel like an inverse cone $[75,76]$. These instabilities cause the liquid jet to decrease in diameter and increase in length. The thickness of the electrified jet should be appropriate to make the desired feature nanofibers. Due to jet movement from the atmosphere, during this process, the solvent evaporates and solid fiber collected at the collector.

If the electrified jet is thin, then we observe splashing due to repulsion between surface charges and no fibers observed on the collector. Mostly instability regions contain multiple jets that are rapidly bending and whipping the threads. The frequency of whipping is high and unable to capture through conventional photography. Many mathematical models are designed to solve bending instability issues. Linear Maxwell equation was proposed to calculate the three-dimensional trajectory for the liquid jet. Most of the mathematical work for the formation of bending instability was done by Reneker, Rutledge, and their coworkers. They proposed different types of models and showed that the spinning process only involves whipping of jet, which is caused by electrostatic interactions between external electric field and surface charges on a liquid jet $[20,77,78]$. During instability, if stretching of the liquid jet is appropriate, then fine fibers produce. But every time it does not happen, so it's necessary to understand the nonlinear rheology of the electrified jet deeply. With the help of these, we can get a control command on the saturation of whipping amplitude, the diameter of the fiber, and the structure of nanofibers. Whenever we do the spinning process, certain limits are applicable in all cases. Like nozzle, which acts as an electrode, must have an inner diameter on the order of $100 \mathrm{~mm}$ and provided a voltage range between 100 to $500 \mathrm{kV}$ in most cases. Collector distance from nozzle plays a significant role in fiber production. In most of the processes, it is between 10 to $25 \mathrm{~cm}$. Moreover, the electrospinning jet can be carried out horizontally or vertically. During jet instability, the cone angle is critical. In most cases, it is $308 \mathrm{oC}$. But it varies because if we apply high voltage, then the scenario is different as compared to if we are applying low voltage.

Applied voltage creates the Taylor cone in jet and polymer melt sprinkle on collector like a shower. But we cannot guess the shape of fibers by visual examination. Sometimes it looks fine, but while using scanning electron microscopy, we come to know there are a lot of bead formation or there shape not flat, it looks like ribbons. So for every polymer melt conditions are different but within a specific range. Nanofibers production with specific shape and dimensions depends on the molecular weight of the polymer, glass transition temperature, solubility, and viscoelasticity, surface tension, electrical conductivity, relative humidity, and the vapor pressure of the solvent, feed rate, collective distance, field strength, electrodes geometry and applied voltage. Like if we decrease the concentration of polymer up to a specific limit, we can produce fibers with less diameter. So we can set our system by hit and trial method to achieve a desired shape of nanofibers. To make different fiber assemblies, mostly, there are two methods. The first one is to control electrified jet by varying electric field and second to choose dynamic collecting device. For in-depth process study, we must be aware of the principle, necessary process, and essential parameters of the whole electrospinning process. It is a continuous and most advanced process as compared to conventional spinning processes like dry spinning, melt spinning, drawing. In this century, many scientists working on this topic and trying to make electrospinning more advanced. In 2003 Kameoka and 2004 Yarin and Zussman discovered the electrospinning process without spinneret $[80,86]$. This discovery makes the spinning process more comfortable and advanced. Now it also becomes possible to produce three-dimensional nanofibers [82]. For 
molten polymers, vacuum electrospinning is also possible, which was introduced by Rangpukan and Reneker [83]. Moreover, at the start of the 21 st century, the University of Massachusetts Institute of Technology introduced a new technique in electrospinning equipment design by nonuniform electric field distribution. They made a versatile configuration with parallel plate geometry, which controls the curvature [84].

Various devices used for the electrospinning process previously. The basic purpose was the same, but everyone focused on some specifications of polymeric fibers. In the Table 1, we discussed all the previous techniques concerning their processing method.

Fast

Acceleration

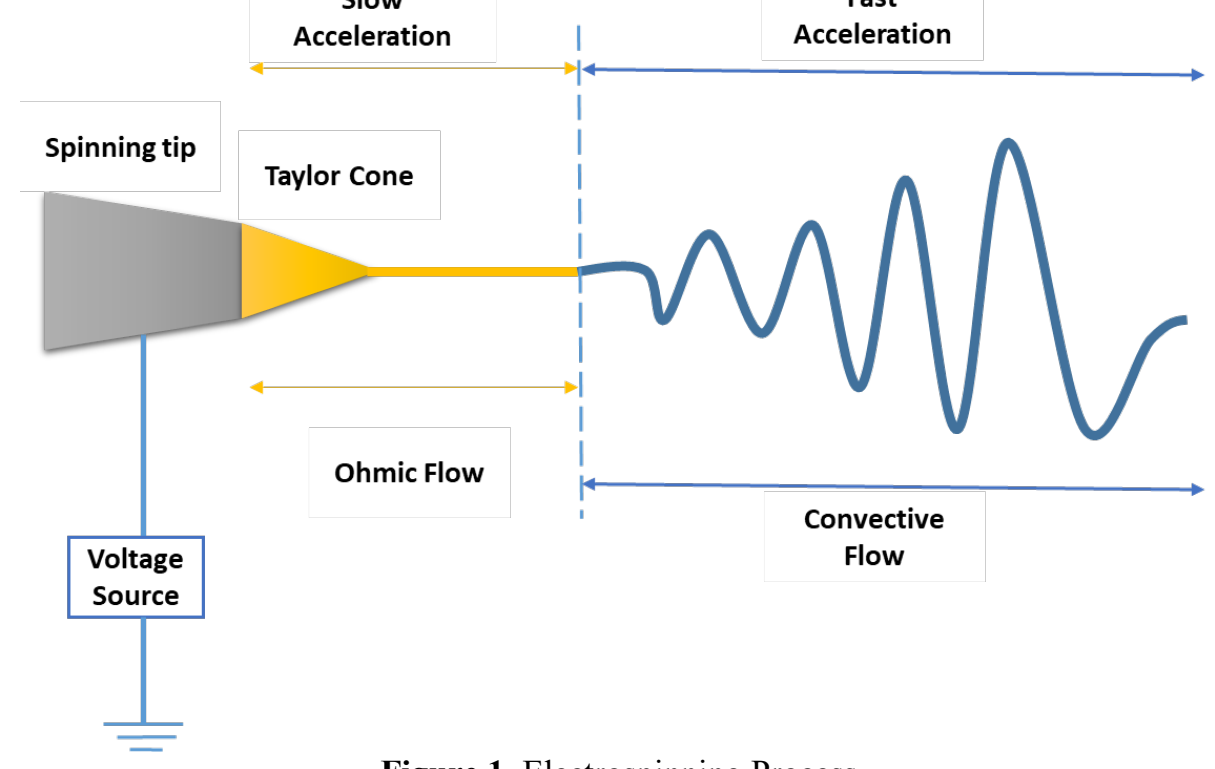

Figure 1. Electrospinning Process

Table 1. Different method of Electrospinning with unique specifications

\begin{tabular}{|c|c|c|}
\hline No. & Electrospinning Methods & $\begin{array}{c}\text { Process specifications } \\
\end{array}$ \\
\hline 1. & $\begin{array}{l}\text { Electrospinning machine with parallel } \\
\text { electrodes }\end{array}$ & $\begin{array}{c}\text { Used for the preparation and ease transfer process of } \\
\text { highly aligned polymeric fibers }\end{array}$ \\
\hline 2. & Rotating wire drum electrospinning & Used for the preparation of thinner fibers \\
\hline 3. & Rotating drum electrospinning & $\begin{array}{c}\text { Provide a large area for the production of the large } \\
\text { fiber }\end{array}$ \\
\hline 4. & $\begin{array}{l}\text { Wire Wounded drum collector } \\
\text { electrospinning }\end{array}$ & Wires help in adjusting the area of polymeric fibers \\
\hline 5. & $\begin{array}{l}\text { Inside Sharpe pin rotating drum } \\
\text { electrospinning }\end{array}$ & A technique used to fabricate the arrayed fibers \\
\hline 6. & Ring collector electrospinning & Used to fabricate the twisted yarns \\
\hline 7. & Coagulation bath electrospinning & $\begin{array}{c}\text { Used to fabricate the long, aligned and continuous } \\
\text { yarns }\end{array}$ \\
\hline 8. & Blade electrospinning & Used to remove the fabricated yarns \\
\hline 9. & Disc collector electrospinning & Prepared highly aligned and arrayed fibers \\
\hline 10. & Rotating tube electrospinning & $\begin{array}{l}\text { The process utilized the knife-edged electrodes to } \\
\text { produce highly aligned thicker fibers }\end{array}$ \\
\hline 11. & Controlling electrospinning & $\begin{array}{l}\text { Spinneret with knife-edgee electrode control the } \\
\text { direction of aligned fibers. }\end{array}$ \\
\hline 12. & Multiple spinneret electrospinning & $\begin{array}{c}\text { Mix fibers of different materials with desired } \\
\text { quantities }\end{array}$ \\
\hline 13. & Counter electrodes electrospinning & Used to fabricate short length fibers \\
\hline
\end{tabular}

\section{IMPORTANT PARAMETERS AND THEIR EFFECTS}

\subsection{Concept of Bending Instabilities}

During the electrospinning process, it's essential to stabilize the viscoelastic stresses in the jet. But electrified jets not always show bending stability. Even when we are providing an equal charge but still all electrically charged jets do not adopt a perfectly straight path in a given provided time. After a specific short length, the electrically charged jet adopts a conical shape at the end of the straight line segment. Electrified jets are bent because of the presence of Coulomb forces. Static Electrical charges follow the coulomb force without the external field and called unstable systems by Earnshaw's theorem [85]. Electrically driven bending instabilities are relating to viscoelastic stresses, which actually dominate the surface tension and also save the process from a capillary breakup. This process is also affected by the polymer concentration. If it is too high or low, it leads to the bead formation [86]. In this process, the liquid fully atomized by the electrical forces, which enhances the capillary instability. If 
we define the bending instability of jet in three dimensional way, we can say it follows a growing amplitude with bending, winding, spiraling, and looping path. This instability process is very continuous, and it shifts from one loop to another as the loop diameter or circumferences change. The bending instability process leads to three necessary steps; first, it creates the straight electrified jet, which generates the bending loop at its endpoint. Then these loops start growing, and in the last, if the loop length increased up to a maximum limit, then loop diameter grows less [87]. Bending instabilities are connected with an area reduction ratio. We can also say this a draw ratio because during the electrospinning process, all the solvent is evaporated.

Area reduction ratio $=$ Cross-sectional area of upper end of loop segment/ Cross-sectional area at the lower end of the loop segment (volume of the segment must be conserved).

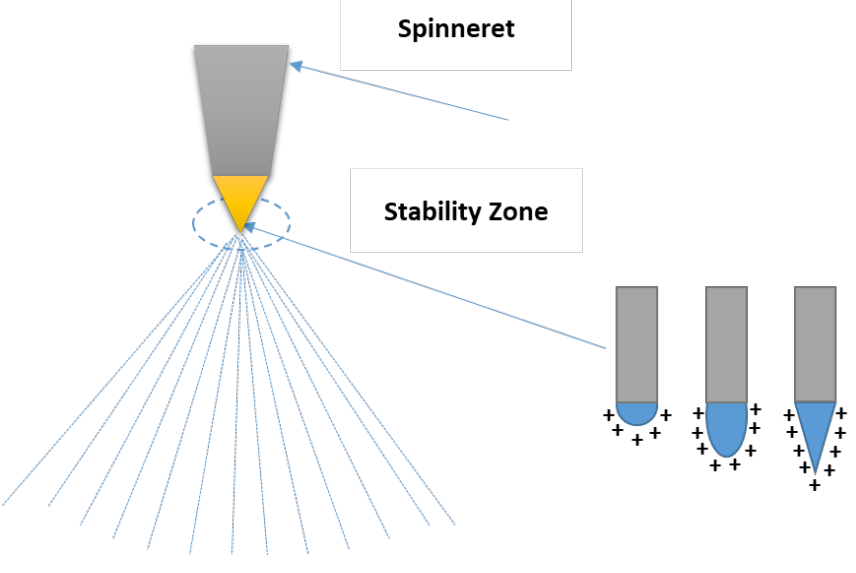

Figure 2. Ejection of fibers and charge deposition

\subsection{Conductivity and Ion mobility}

For the electrospinning process, the solution must be conductive, so that electric charge can transfer from electrode to polymer droplet. But in some cases, polymer shows its polyelectrolyte properties, which can increase solution conductivity [88]. When we apply the electric field to the polymeric solution for the electrospinning process, it's referred to as a vast range of excess electrical charges. We can explain the term of excess charge as that when electrically influenced polymeric solution moves, positive and negative ions move in the opposite direction. They attracted to particular electrodes, and their difference in number is considered as an excess charge. The electrical conductivity of the solution controls the ability of the solution to form nanofibers continuously without any formation of Nano drops.

During the electrospinning process of the polymer solution, ions show various types of mobility. In most of the cases, it is near around 10-6m $2 / \mathrm{Vs}$ [89, 90]. While considering ion mobility, conventionally, we observed the velocity of the last segment of the straight jet. It's possible to assume that all ionic charges are moving with jet with a fixed charge to simplify our calculations. When we mix the polymers with solvent, solution conductivity increase because of the presence of ions. But if we increase the amount of solvent or polymer, then it may affect the ions availability [91].

The electric field can be determined like
Electric field $=$ Applied Potential / Distance between the surface of pendant drop and collector plate

If we face a problem with the availability of ions, then we can also add electrolyte, which can help in smooth fiber production with small-diameter [92]. Ions also affect the morphology and diameter of nanofibers. When they have high mobility with small size, they produce the small-diameter fibers. High Ionic mobility helps to reduce the number of flaws present in nanofibers, plus it also uniforms the size of nanofibers by creating a high tensile force for the jet of polymeric solution [93].

\subsection{Electro-spun Jet Motion}

During electrospinning, nanofibers are formed by electrospun jets. A charge is provided to jet and air act as a dragging agent to cover up the collector surface by nanofibers. Jet show bend, wind, spiral, and loop type path in terms of three-dimensional effects. We can collect the nanofibers on different surfaces according to our experimental requirements, like aluminum foil, glass plates, metal screens, or any other solid surface. If the jet is showing some small bending instabilities, then nanofibers collect in the coiled or looped shape. As the loop diameter starts increasing, jet also becomes long and thin.

We can observe their mechanical gravity-driven effect by the camera. During mechanical buckling, some long jets tried to adopt sidewise roots and solidified before coming towards the collector. Jet segments always adopt different cycles and develop new bending instabilities at a smaller level. Sometimes, jet split into two or more parts perpendicular to the axis of the jet. They are considered to produce from below the apex of the cone. These small parts are for a short time and disappear soon and do not create some bending instabilities.

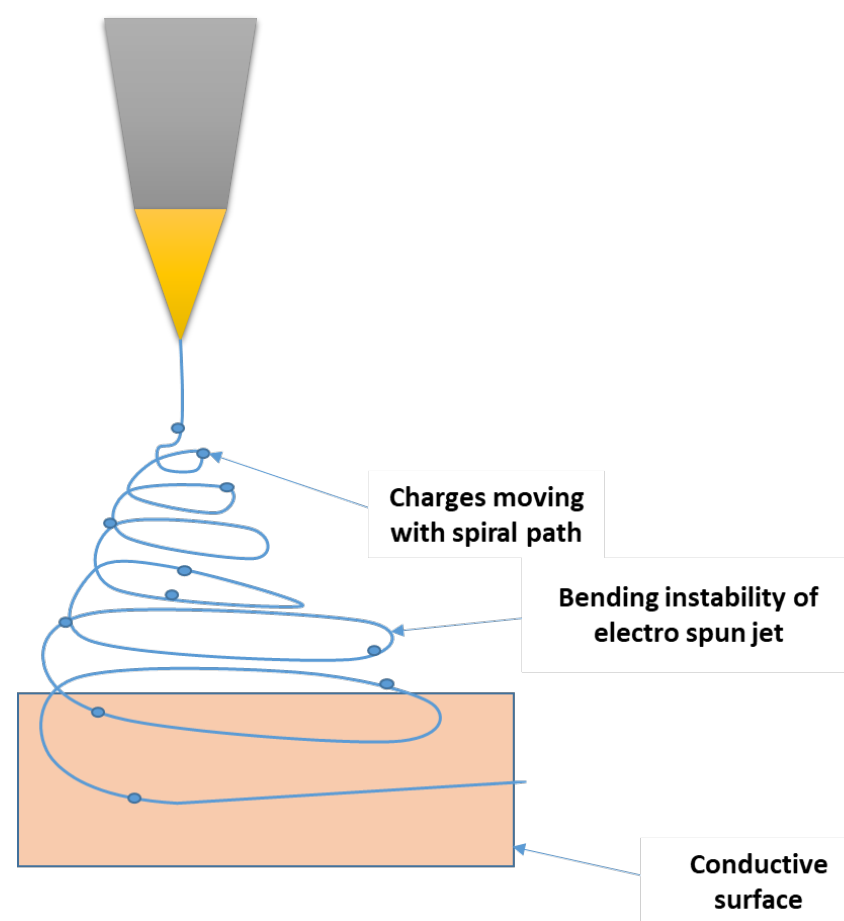

Figure 3. Electro-spun jet motion 


\subsection{Salt effects}

By adding some salt in our polymeric solution, create equivalent ionic dissociation, and enhance the number of ions per unit volume of solution. An increase in conductivity may result in less time for an excess charge, but it cannot affect the excess charge. Many inorganic salts like Trialchilbenzil ammonium chloride [94, 95], Palladium diacetate [96], Pyridiniumformate (PF) [97] and sodium chloride $(\mathrm{NaCl})$ [98100] are used to increase the conductivity of polymer solution. The concentration of salt and polymer both effect the spin ability, morphology, and diameter of nanofibers. To prove our facts, we take a system in which lithium chloride salt is used for Polyurethane (PU) polymer (Figure 4) to increase the spinning ability of PU [101].

Composite bonding starts creating between dimethylformamide solvent and PU polymer. PU and LiClhave the same bonding as H-bridges (Figure 5). Intermolecular interactions created by polar groups help LiClto makes the functional groups of PU more polar.

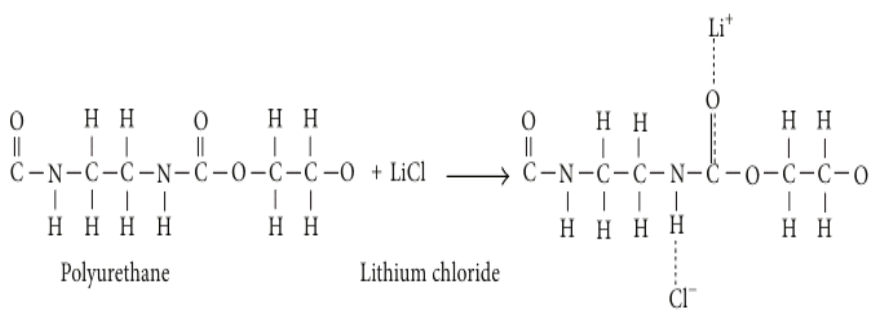

Figure 4. Effect of lithium chloride salt in polyurethane solution

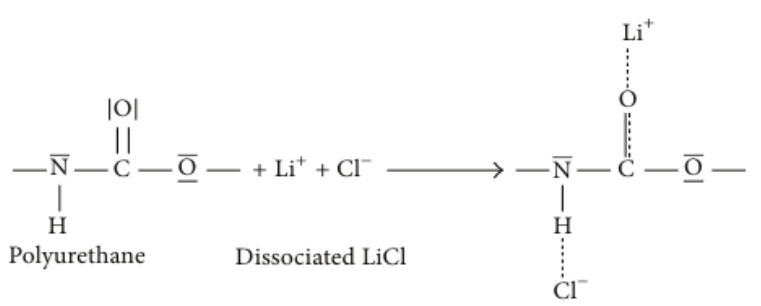

Figure 5. Intermolecular interactions of $\mathrm{LiCl}$ with Polyurethane

The addition of salt increases the viscosity, spinning ability, polarity, and conductivity and decrease the diameter of nanofibers. All of the factors are strongly dependent on the dielectric properties of the polymeric solution. We can see by the given results. But the extreme increase of parameters doesn't ensure the quality of fibers.

We come to know the change in viscosity basically because of partial re-coordination of lithium cations with DMF and from DMF carbonyl group to PU carbonyl groups to form intermolecular crosslinks [102]. In figures spinning shows the same behavior as several jets. We can apply the theory of shielding effect here. The electric field seems to be screened out near the conical space of the conductor [103].

\section{APPLICATIONS}

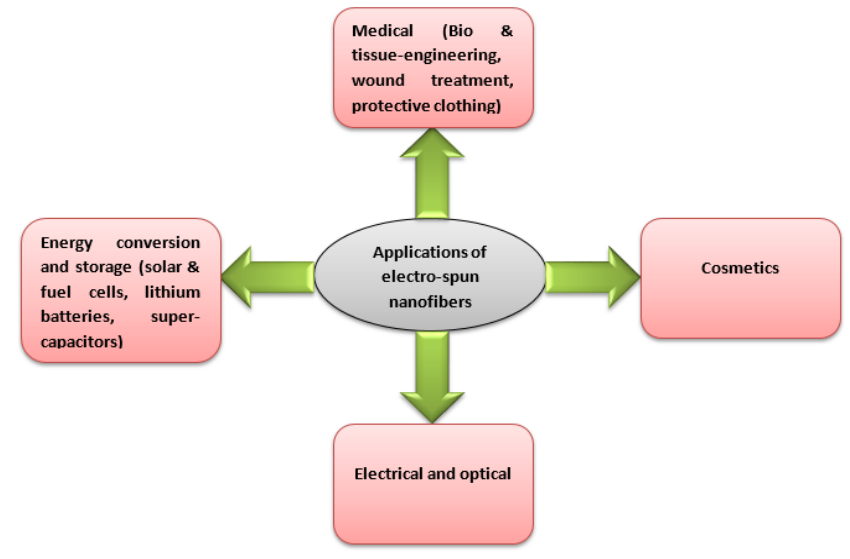

Figure 6. Applications of electro spun nanofibers in different fields

Applications of electrospinning polymeric fibers covered the industry and academic areas. The importance of this field leads to its research level from laboratory work to applied industry. Polymeric nanofibers played an essential role in the field of medicine as stunned fibers are highly used in biomedical applications, medical treatments, tissue engineering, and wound dressing and especially in drug delivery processes. Moreover, other applications involved filtration applications, use in cosmetics, protective clothing, electrical, optical, and functional applications, shown in Figure 6.

\subsection{Bio-engineering Applications}

Human body composed of nano-fibrous structured tissues and organs like bones, skin, collagen. Electrospun nanofibers utilized for biomedical applications nowadays. Polyglycolic acid, poly ethylene-co-vinyl acetate, and collagen are fabricated through the biomaterial electrospinning process introduced by Bowling et al. [104]. Another approach was utilized to introduce the insoluble particles inside of polymeric nanofibers, which referred to as encapsulation electrospinning by Reneker's group [105]. Pollen spore and biomaterials added for multi-purposes like wound healing as electrospun fibers can adjust the $\mathrm{pH}$, drug delivery, or antibacterial functions to protect from contaminations to functionalize the fibers gold or silver alloys. Artificial skin production could also be possible through direct electrospinning.

\subsection{Tissue-engineering Applications}

The use of electrospun polymeric nanofibers in tissue engineering created a great versatility in the research field. Ideal scaffold nanofiber structures that tend to obtain phenotypic shape supports in cell growth, attachments, and proliferation. The morphology of electrospun nanofibers is characterized through the diameter, porosity, mechanical strength, and scaffold mechanism. Matthews et al. worked on the tissue engineering of collagen nanofibers, fibers spun by using origin tissues, isotopes, and collagen concentration. In most cases, non-woven fiber networks are prepared by the help of electrospinning of weak acid collagen solution at standard temperature and pressure [106]. 


\subsection{Medical Applications}

Electrospun polymer nanofibers are very biocompatible due to their porous thin film structure. Mostly they are utilized in the devices which are used to be implanted in the human body; these may be referred to as soft tissue prostheses application. For the compatible bonding between obturator and host tissues, fibrous material must present an incline in coating film, which acts as interphase. This may lead to a reduction in the inconsistency between devices and tissues. This technology utilized in many human body transplantations like blood vessels, heart, vascular, breast, etc. [107-110].

\subsection{Wound Treatment}

Electrospun biodegradable polymeric nanofibers have vast applications in the wound or burn treatment of skin. Specially they play an essential role in response to blood injury or bleeding by developing interactions between platelets and blood clotting proteins to make a clot to stop the bleeding. The benefit of this technique is that when we directly spray the fibers on the skin through the electric field, it eliminates the formation of scars. The pore size of the fibers varied in this field depending upon the wound size because we must assure the protection of the wound from bacterial penetration and air particles [111-113].

\subsection{Cosmetics}

The cosmetic industry is always looking forward to getting fast results for glowing skin beauty. Another beneficial application of nanofibers is their role in skincare masks, which used to heal, clean, or glow the skin. Their porous structure and high surface area facilitate the cosmetic additives to provide fast and better results without any pain or itching effect. Skin treatment carried by nanofibers masks is more efficient than traditional creams or lotions as they may harm the sensitive skin especially eyes, nose, and lips during their application on the face because they involve chemicals [114].

\subsection{Protective Clothing}

Electrospun nanofibers possess a unique property of chemical neutralization, which leads to its usage in protective clothing for soldiers and scientists. Nanofibers with high surface area and the porous structure can neutralize the chemicals and reduce the air resistance and water permeability effects. In the same manner, scientists also use this during very sensitive experiments. Protective clothing does not refer to dress; it also includes shoes, face masks, gloves, goggles, and breathing devices. Previously used protective clothing's been quite substantial and has some flaws like charcoal absorbents have limitations in water permeability. In comparison to previous techniques, electrospun polymer nanofibers are the most unique and efficient [115-117].

\subsection{Electrical and optical Applications}

Nanofibers possess a versatile property of conductance and utilized in the fabrication of electronic devices, especially in sensors. In the field of electrochemical engineering, conductive nanofiber membranes are used for photovoltaic devices, liquid crystal, corrosion protection, electronic dissipation, and electromagnetic shielding. Many fibrous membranes are utilized for water purification. The pore size and surface area of the fibrous membrane are significant, which reflect the sensitivity of the system and refractive index between the electrodes [118].

\subsection{PV solar cell materials}

The electrospinning method is used to develop the materials for the fabrication of solar cells: one-dimensional hybrid, organic and inorganic nanomaterials prepared either in oriented form or random nanofiber structures. Our main concern is to focus on the internal morphology of nanofibers; they could be hollow, porous, or multi-channeled. In solar cells, nanofibers are used for electrode and electrolyte materials. The fundamental properties required from them are high surface area, low density, and high pore volume, which enhance the efficiency of solar energy conversion devices [119]. Most recently, the discussed study for solar cell materials is the utilization of LiMn2O4 nanofibers. They are characterized by SEM, XRD, FTIR, and cyclic voltammetry. The porous and hollow structure of LiMn2O4 nanofibers used as a cathode material provides an active mass area, dual conduction of $\mathrm{Li}+$, and electrons for the effective structural strain and volume change. It will enhance cyclic performance and possess excellent stability [120].

\subsection{Electrocatalysts for electrochemical energy conversion and storage}

Currently, in the world, there is a shortage of energy resources and also a lot of environmental problems associated with them. Nowadays, scientists focus on the development of clean and efficient energy storage devices. Nanofibers are used in many energy storage devices like lithium batteries, LIBs, LSBs, and Li-O2 batteries), fuel-cells, solar-cells, and supercapacitors. They provide high surface area and porous structure. Their specific morphology developed systematically through the electrospinning technique. Nanofibers are used as electrode material or separators. In lithium-based batteries, they provide high power capability and good kinetic properties due to a decrease in the length of the lithium-ion diffusion pathway. In fuel cells, nanofibers mostly act as electrocatalysts for electrodes, which enhance durability. While in electrolyte membranes where they act as separators present high electrolyte uptake and ionic conductivity. Moreover, they are responsible for high photoelectric conversion efficiency in solar cells and high capacities in supercapacitors [121].

\section{CONCLUSION}

The review focused on summarizing the significant contributions in the field of electrospinning. A brief historic discussion provides enough information on the innovations carrying path. Due to Advanced developments, the field becomes diverse, and a variety of methods have been introduced with process specifications. At the same time, problems are also associated with the electro-spun polymeric nanofibers either during preparation or after. Through this review, main parameters and their effects on electrospinning are highlighted. These effects referred to problems and their solutions too. Moreover, the enormous potential of polymeric nanofibers plays a vital role in many critical applications of human life, like in the medical, electrical, optical fields. PV 
solar cell fabrication and elaboration of electrocatalysts for electrochemical energy conversion and storage. In conclusion, the review described the progress of evolution and innovation in the field of electrospinning, from its history to the modern aspect.

\section{REFERENCES}

[1] Aliabadi, M., Irani, M., Ismaeili, J., Piri, H., Parnian, M. J. (2013). Electrospun nanofiber membrane of PEO/Chitosan for the adsorption of nickel, cadmium, lead and copper ions from aqueous solution. Chemical engineering journal, 220: 237-243. https://doi.org/10.1016/j.cej.2013.01.021

[2] Alipour, S.M., Nouri, M., Mokhtari, J., Bahrami, S.H. (2009). Electrospinning of poly (vinyl alcohol)-watersoluble quaternized chitosan derivative blend. Carbohydrate Research, 344(18): 2496-2501. https://doi.org/10.1016/j.carres.2009.10.004

[3] Angammana, C.J., Jayaram, S.H. (2011). Analysis of the effects of solution conductivity on electrospinning process and fiber morphology. IEEE Transactions on industry applications, 47(3): 1109-1117. https://doi.org/10.1109/TIA.2011.2127431

[4] Bae, H.S., Haider, A., Selim, K.K., Kang, D.Y., Kim, E.J., Kang, I.K. (2013). Fabrication of highly porous PMMA electrospun fibers and their application in the removal of phenol and iodine. Journal of Polymer Research, 20(7): 158. https://doi.org/10.1007/s10965013-0158-9

[5] Baniasadi, M., Huang, J., Xu, Z., Moreno, S., Yang, X., Chang, J., Minary-Jolandan, M. (2015). Highperformance coils and yarns of polymeric piezoelectric nanofibers. ACS applied materials \& interfaces, 7(9): 5358-5366. https://doi.org/10.1021/am508812a

[6] Bhardwaj, N., Kundu, S.C. (2010). Electrospinning: a fascinating fiber fabrication technique. Biotechnology advances, $\quad 28(3)$ : 325-347. https://doi.org/10.1016/j.biotechadv.2010.01.004

[7] Teo, W.E., Ramakrishna, S. (2006). A review on electrospinning design and nanofibre assemblies. Nanotechnology, $\quad$ 17(14): R89. https://doi.org/10.1088/0957-4484/17/14/R01

[8] Frenot, A., Chronakis, I.S. (2003). Polymer nanofibers assembled by electrospinning. Current opinion in colloid \& interface science, 8(1): 64-75. https://doi.org/10.1016/S1359-0294(03)00004-9

[9] Huang, Z.M., Zhang, Y.Z., Kotaki, M., Ramakrishna, S. (2003). A review on polymer nanofibers by electrospinning and their applications in nanocomposites. Composites science and technology, 63(15): 2223-2253. https://doi.org/10.1016/S02663538(03)00178-7

[10] Gupta, K.C., Haider, A., Choi, Y.R., Kang, I.K. (2014). Nanofibrous scaffolds in biomedical applications. Biomaterials research, 18(1): 1-11. https://doi.org/10.1186/2055-7124-18-5

[11] Feng, L., Li, S., Li, H., Zhai, J., Song, Y., Jiang, L., Zhu, D. (2002). Superhydrophobic surface of aligned polyacrylonitrile nanofibers. Angewandte Chemie International Edition, 41(7): 1221-1223. https://doi.org/10.1002/1521-
3773(20020402)41:7<1221::AID-ANIE1221>3.0.CO;2$\mathrm{G}$

[12] Haider, S., Binagag, F.F., Haider, A., Mahmood, A., Al Masry, W.A., Alhoshan, M., Khan, S.U.D. (2015). Fabrication of the diethylenetriamine grafted polyacrylonitrile electrospun nanofibers membrane for the aqueous removal of cationic dyes. Science of Advanced $\quad$ Materials, 7(2): 309-318. https://doi.org/10.1166/sam.2015.2023

[13] Haider, A., Gupta, K.C., Kang, I.K. (2014). Morphological effects of HA on the cell compatibility of electrospun HA/PLGA composite nanofiber scaffolds. BioMed research international, 2014. Article ID 308306. https://doi.org/10.1155/2014/308306

[14] Whitesides, G.M., Grzybowski, B. (2002). Self-assembly at all scales. Science, 295(5564): 2418-2421. https://doi.org/10.1126/science.1070821

[15] Haider, S., Binagag, F.F., Haider, A., Mahmood, A., Shah, N., Al-Masry, W.A., Ramay, S.M. (2015). Adsorption kinetic and isotherm of methylene blue, safranin $\mathrm{T}$ and rhodamine $\mathrm{B}$ onto electrospun ethylenediamine-grafted-polyacrylonitrile nanofibers membrane. Desalination and Water Treatment, 55(6): 1609-1619. https://doi.org/10.1080/19443994.2014.926840

[16] Deitzel, J.M., Kleinmeyer, J.D., Hirvonen, J.K., Tan, N.B. (2001). Controlled deposition of electrospun poly (ethylene oxide) fibers. Polymer, 42(19): 8163-8170. https://doi.org/10.1016/S0032-3861(01)00336-6

[17] Fong, H, Electrospinning and formation of nanofibers, Structure formation in polymeric fibers. Munich, 2001.

[18] Liu, Y., He, J.H., Yu, J.Y., Zeng, H.M. (2008). Controlling numbers and sizes of beads in electrospun nanofibers. Polymer International, 57(4): 632-636. https://doi.org/10.1002/pi.2387

[19] Haider, S., Al-Zeghayer, Y., Ali, F.A.A., Haider, A., Mahmood, A., Al-Masry, W.A., Aijaz, M.O. (2013). Highly aligned narrow diameter chitosan electrospun nanofibers. Journal of Polymer Research, 20(4): 105. https://doi.org/10.1007/s10965-013-0105-9

[20] Chronakis, I.S. (2005). Novel nanocomposites and nanoceramics based on polymer nanofibers using electrospinning process - a review. Journal of materials processing technology, 167(2-3): 283-293. https://doi.org/10.1016/j.jmatprotec.2005.06.053

[21] Reneker, D.H., Yarin, A.L., Fong, H., Koombhongse, S. (2000). Bending instability of electrically charged liquid jets of polymer solutions in electrospinning. Journal of Applied physics, 87(9): 4531-4547. https://doi.org/10.1063/1.373532

[22] Yarin, A.L., Koombhongse, S., Reneker, D.H. (2001). Bending instability in electrospinning of nanofibers. Journal of applied physics, 89(5): 3018-3026. https://doi.org/10.1063/1.1333035

[23] Yarin, A.L., Koombhongse, S., Reneker, D.H. (2001). Taylor cone and jetting from liquid droplets in electrospinning of nanofibers. Journal of applied physics, 90(9): 4836-4846. https://doi.org/10.1063/1.1408260

[24] Shin, Y.M., Hohman, M.M., Brenner, M.P., Rutledge, G.C. (2001). Experimental characterization of electrospinning: the electrically forced jet and instabilities. Polymer, 42(25): 09955-09967.

[25] He, J.H., Wan, Y.Q. (2004). Allometric scaling for voltage and current in electrospinning. Polymer, 45(19): 
6731-6734.

https://doi.org/10.1016/j.polymer.2004.07.064

[26] Qin, X.H., Wan, Y.Q., He, J.H., Zhang, J., Yu, J.Y., Wang, S.Y. (2004). Effect of $\mathrm{LiCl}$ on electrospinning of PAN polymer solution: Theoretical analysis and experimental verification. Polymer, 45(18): 6409-6413. https://doi.org/10.1016/j.polymer.2004.06.031

[27] Frenot, A., Chronakis, I.S. (2003). Polymer nanofibers assembled by electrospinning. Current opinion in colloid \& interface science, 8(1): 64-75. https://doi.org/10.1016/S1359-0294(03)00004-9

[28] Li, D., Xia, Y. (2004). Electrospinning of nanofibers: reinventing the wheel? Advanced materials, 16(14): 1151-1170. https://doi.org/10.1002/adma.200400719

[29] Deitzel, J.M., Kleinmeyer, J., Harris, D.E.A., Tan, N.B. (2001). The effect of processing variables on the morphology of electrospun nanofibers and textiles. Polymer, 42(1): 261-272. https://doi.org/10.1016/S00323861(00)00250-0

[30] Wang, H., Liu, Q., Yang, Q., Li, Y., Wang, W., Sun, L., Li, Y. (2010). Electrospun poly (methyl methacrylate) nanofibers and microparticles. Journal of materials science, $\quad 45(4)$ : 1032-1038 https://doi.org/10.1007/s10853-009-4035-1

[31] Haider, A., Gupta, K.C., Kang, I.K. (2014). PLGA/nHA hybrid nanofiber scaffold as a nanocargo carrier of insulin for accelerating bone tissue regeneration. Nanoscale research letters, 9(1): 314. https://doi.org/10.1186/1556-276X-9-314

[32] Haider, S., Binagag, F.F., Haider, A., Mahmood, A., Al Masry, W.A., Alhoshan, M., Khan, S.U.D. (2015). Fabrication of the diethylenetriamine grafted polyacrylonitrile electrospun nanofibers membrane for the aqueous removal of cationic dyes. Science of Advanced Materials, 7(2): 309-318. https://doi.org/10.1166/sam.2015.2023

[33] Haider, S., Haider, A., Ahmad, A., Khan, S.U.D., Almasry, W.A., Sarfarz, M. (2015). Electrospun Nanofibers affinity membranes for water hazards remediation. Nanotechnology Research Journal, 8(4): 511.

[34] Bognitzki, M., Frese, T., Steinhart, M., Greiner, A., Wendorff, J.H., Schaper, A., Hellwig, M. (2001). Preparation of fibers with nanoscaled morphologies: Electrospinning of polymer blends. Polymer Engineering \& Science, 41(6): 982-989. https://doi.org/10.1002/pen.10799

[35] Jayaraman, K., Kotaki, M., Zhang, Y., Mo, X., Ramakrishna, S. (2004). Recent advances in polymer nanofibers. Journal of Nanoscience and Nanotechnology, 4(1-2): 52-65. https://doi.org/10.1166/jnn.2004.078

[36] Subbiah, T., Bhat, G.S., Tock, R.W., Parameswaran, S., Ramkumar, S.S. (2005). Electrospinning of nanofibers. Journal of applied polymer science, 96(2): 557-569. https://doi.org/10.1002/app.21481

[37] Dersch, R., Steinhart, M., Boudriot, U., Greiner, A., Wendorff, J.H. (2005). Nanoprocessing of polymers: applications in medicine, sensors, catalysis, photonics. Polymers for Advanced Technologies, 16(2-3): 276-282. https://doi.org/10.1002/pat.568

[38] Koombhongse, S., Liu, W., Reneker, D.H. (2001). Flat polymer ribbons and other shapes by electrospinning. Journal of Polymer Science Part B: Polymer Physics, 39(21): 2598-2606. https://doi.org/10.1002/polb.10015
[39] Zong, X., Kim, K., Fang, D., Ran, S., Hsiao, B.S., Chu, B. (2002). Structure and process relationship of electrospun bioabsorbable nanofiber membranes. Polymer, 43(16): 4403-4412. https://doi.org/10.1016/S0032-3861(02)00275-6

[40] Tang, Z., Qiu, C., McCutcheon, J.R., Yoon, K., Ma, H., Fang, D., Lee, E., Kopp, C., Hsiao, B.S., Chu, B. (2009). Design and fabrication of electrospun polyethersulfone nanofibrous scaffold for high-flux nanofiltration membranes. Journal of Polymer Science Part B: Polymer Physics, 47(22): 2288-2300. https://doi.org/10.1002/polb.21831

[41] Ledezma-Oblea, J.G., Morales-Sánchez, E., GaytánMartínez, M., Figueroa-Cárdenas, J.D., Gaona-Sánchez, V.A. (2015). Corn starch nanofilaments obtained by electrospinning. Revista Mexicana de Ingeniería Química, 14(2): 497-502. http://www.rmiq.org/ojs311/index.php/rmiq/article/view $/ 1276$

[42] Komur, B., Bayrak, F., Ekren, N., Eroglu, M.S., Oktar, F.N., Sinirlioglu, Z.A., Gunduz, O. (2017). Starch/PCL composite nanofibers by co-axial electrospinning technique for biomedical applications. Biomedical engineering online, 16(1): 1-13. https:/doi.org/10.1186/s12938-017-0334-y

[43] John Zeleny. (1917). Instability of electrified liquid surfaces. Physical review Vol. X (1). https://doi.org/10.1103/PhysRev.10.1

[44] Kiyohiko Hagiwara., (1929). Process for manufacturing artificial silk and other filaments by applying electric current. United states patent office, 1699615.

[45] Fang, J., Niu, H., Wang, H., Wang, X., Lin, T. (2013). Enhanced mechanical energy harvesting using needleless electrospun poly (vinylidene fluoride) nanofibre webs. Energy \& Environmental Science, 6(7): 2196-2202. https://doi.org/10.1039/C3EE24230G

[46] Subbiah, T., Bhat, G.S., Tock, R.W., Parameswaran, S., Ramkumar, S.S. (2005). Electrospinning of nanofibers. Journal of applied polymer science, 96(2): 557-569. https://doi.org/10.1002/app.21481

[47] Reneker, D.H., Chun, I. (1996). Nanometre diameter fibres of polymer, produced by electrospinning. Nanotechnology, 7(3): 216. https://doi.org/10.1088/0957-4484/7/3/009

[48] Valizadeh, A., Farkhani, S.M. (2013). Electrospinning and electrospun nanofibres. IET nanobiotechnology, 8(2): 83-92. https://doi.org/10.1049/iet-nbt.2012.0040

[49] Matsumoto, H., Tanioka, A. (2011). Functionality in electrospun nanofibrous membranes based on fiber's size, surface area, and molecular orientation. Membranes, 1(3): 249-264. https://doi.org/10.3390/membranes 1030249

[50] Peter K Baumgarten., (1971). Electrostatic Spinning of Acrylic Microfibers. journal of collide and interface science, 36(1): 71-79. https://doi.org/10.1016/00219797(71)90241-4

[51] Reneker, D.H., Kataphinan, W., Theron, A., Zussman, E., Yarin, A.L. (2002). Nanofiber garlands of polycaprolactone by electrospinning. Polymer, 43(25): 6785-6794. https://doi.org/10.1016/S00323861(02)00595-5

[52] Xin, Y., Reneker, D.H. (2012). Garland formation process in electrospinning. Polymer, 53(16): 3629-3635. https://doi.org/10.1016/j.polymer.2012.05.060 
[53] Larrondo, L.S.J.M., St. John Manley, R. (1981). Electrostatic fiber spinning from polymer melts. I. Experimental observations on fiber formation and properties. Journal of Polymer Science: Polymer Physics Edition, 19(6):

909-920. https://doi.org/10.1002/pol.1981.180190601

[54] Larrondo, L., St. John Manley, R. (1981). Electrostatic fiber spinning from polymer melts. II. Examination of the flow field in an electrically driven jet. Journal of Polymer Science: Polymer Physics Edition, 19(6): 921-932. https://doi.org/10.1002/pol.1981.180190602

[55] Larrondo, L., St. John Manley, R. (1981). Electrostatic fiber spinning from polymer melts. III. Electrostatic deformation of a pendant drop of polymer melt. Journal of Polymer Science: Polymer Physics Edition, 19(6): 933-940. https://doi.org/10.1002/pol.1981.180190603

[56] I Hayati, A.I Bailey, Th.F Tadros., (1987). Investigations into the mechanisms of electrohydrodynamic spraying of liquids: I. Effect of electric field and the environment on pendant drops and factors affecting the formation of stable jets and atomization. journal of collide and interface $\quad$ science, $117(1)$ : 205-221. https://doi.org/10.1016/0021-9797(87)90185-8)

[57] Du, Q., Harding, D.R., Yang, H. (2013). Helical peanutshaped poly (vinyl pyrrolidone) ribbons generated by electrospinning. Polymer, 54(25): 6752-6759. https://doi.org/10.1016/j.polymer.2013.10.029

[58] Stranger J., Tucker N., Staiger M., Electrospinning. Smithers Rapra, Shrewsbury, Shropshire, GBR, 2009.

[59] Koombhongse, S., Liu, W., Reneker, D.H. (2001). Flat polymer ribbons and other shapes by electrospinning. Journal of Polymer Science Part B: Polymer Physics, 39(21): 2598-2606. https://doi.org/10.1002/polb.10015

[60] Li, Z., Wang, C. (2013). Effects of working parameters on electrospinning. In One-dimensional nanostructures, 15-28. https://doi.org/10.1007/978-3-642-36427-3_2

[61] Wendorff, J.H., Agarwal, S., Greiner, A. (2012). Electrospinning: materials, processing, and applications. John Wiley \& Sons.

[62] De Vrieze, S., Van Camp, T., Nelvig, A., Hagström, B., Westbroek, P., De Clerck, K. (2009). The effect of temperature and humidity on electrospinning. Journal of materials science, 44(5): 1357-1362. https://doi.org/10.1007/s10853-008-3010-6

[63] Şener, A.G., Altay, A.S., Altay, F. (2011). Effect of voltage on morphology of electrospun nanofibers. In 2011 7th International Conference on Electrical and Electronics Engineering (ELECO), I-324.

[64] Pirani, S., Abushammala, H.M., Hashaikeh, R. (2013). Preparation and characterization of electrospun PLA/nanocrystalline cellulose-based composites. Journal of Applied Polymer Science, 130(5): 3345-3354. https://doi.org/10.1002/app.39576

[65] Spivek, A. F.; Dzenis, Y. A. Inst Penn Conf 1999, 163, 175.

[66] Xiong, J., Huo, P., Ko, F.K. (2009). Fabrication of ultrafine fibrous polytetrafluoroethylene porous membranes by electrospinning. Journal of Materials Research, 24(9): 2755-2761. https://doi.org/10.1557/jmr.2009.0347

[67] Li, D., Wang, Y., Xia, Y. (2003). Electrospinning of polymeric and ceramic nanofibers as uniaxially aligned arrays. Nano letters, 3(8): 1167-1171. https://doi.org/10.1021/n10344256
[68] Smit, E., Büttner, U., Sanderson, R.D. (2005). Continuous yarns from electrospun fibers. Polymer, 46(8):

2419-2423. https://doi.org/10.1016/j.polymer.2005.02.002

[69] Teo, W.E., Ramakrishna, S. (2006). A review on electrospinning design and nanofibre assemblies. Nanotechnology, $17(14)$ :

R89. https://doi.org/10.1088/0957-4484/17/14/R01

[70] Teo, W.E., Inai, R., Ramakrishna, S. (2011). Technological advances in electrospinning of nanofibers. Science and technology of advanced materials, 12(1): 013002. https://doi.org/10.1088/1468-6996/12/1/013002

[71] Yoo, H.S., Kim, T.G., Park, T.G. (2009). Surfacefunctionalized electrospun nanofibers for tissue engineering and drug delivery. Advanced drug delivery reviews, 61(12): 1033-1042. https://doi.org/10.1016/j.addr.2009.07.007

[72] Huang, C., Soenen, S.J., Rejman, J., Trekker, J., Chengxun, L., Lagae, L., De Smedt, S.C. (2012). Magnetic electrospun fibers for cancer therapy. Advanced Functional Materials, 22(12): 2479-2486. https://doi.org/10.1002/adfm.201102171

[73] Fang, J., Niu, H., Lin, T., Wang, X. (2008). Applications of electrospun nanofibers. Chinese science bulletin, 53(15): 2265. https://doi.org/10.1007/s11434-008-03190

[74] Hohman, M.M., Shin, M., Rutledge, G., Brenner, M.P. (2001). Electrospinning and electrically forced jets. I. Stability theory. Physics of fluids, 13(8): 2201-2220. https://doi.org/10.1063/1.1383791

[75] Zuo, W., Zhu, M., Yang, W., Yu, H., Chen, Y., Zhang, Y. (2005). Experimental study on relationship between jet instability and formation of beaded fibers during electrospinning. Polymer Engineering \& Science, 45(5): 704-709. https://doi.org/10.1002/pen.20304

[76] Reneker, D.H., Yarin, A.L., Fong, H., Koombhongse, S. (2000). Bending instability of electrically charged liquid jets of polymer solutions in electrospinning. Journal of Applied physics, 87(9): 4531-4547. 10.1063/1.373532

[77] Shin, Y.M., Hohman, M.M., Brenner, M.P., Rutledge, G.C. (2001). Experimental characterization of electrospinning: The electrically forced jet and instabilities. Polymer, 42(25): 09955-09967. https://doi.org/10.1016/S0032-3861(01)00540-7

[78] Smith, L.A., Ma, P.X. (2004). Nano-fibrous scaffolds for tissue engineering. Colloids and surfaces B: Biointerfaces, 39(3): 125-131. https://doi.org/10.1016/j.colsurfb.2003.12.004

[79] Frenot, A., Chronakis, I.S. (2003). Polymer nanofibers assembled by electrospinning. Current Opinion in Colloid \& Interface Science, 8(1): 64-75. https://doi.org/10.1016/S1359-0294(03)00004-9

[80] Doshi, J., Reneker, D.H. (1995). Electrospinning process and applications of electrospun fibers. Journal of Electrostatics, 35(2-3): 151-160. https://doi.org/10.1016/0304-3886(95)00041-8

[81] Ichimori, T., Mizuma, K., Uchida, T., Yamazaki, S., Kimura, K. (2013). Morphological diversity and nanofiber networks of poly ( $\mathrm{p}$-oxybenzoyl) generated by phase separation during copolymerization. Journal of applied polymer science, 128(2): 1282-1290. https://doi.org/10.1002/app.38554

[82] Shao, J., Chen, C., Wang, Y., Chen, X., Du, C. (2012). Early stage evolution of structure and nanoscale property 
of nanofibers in thermally induced phase separation process. Reactive and Functional Polymers, 72(10): 765772.

https://doi.org/10.1016/j.reactfunctpolym.2012.07.011

[83] Ramakrishna, S. (2005). An introduction to electrospinning and nanofibers. World Scientific.

[84] Rangkupan, R., Reneker, D.H. (2001). Development of electrospinning from molten polymers in vacuum. New Frontiers in Fiber Science, Raleigh, NC.

[85] Warner, S.B., Buer, A., Ugbolue, S.C., Rutledge, G.C., Shin, M.Y. (1998). A fundamental investigation of the formation and properties of electrospun fibers. National textile center annual report, 83-90.

[86] Jeans, J.H. (1911). The mathematical theory of electricity and magnetism. University Press.

[87] Reneker, D.H., Yarin, A.L., Zussman, E., Xu, H. (2007). Electrospinning of nanofibers from polymer solutions and melts. Advances in applied mechanics, 41: 43-346. https://doi.org/10.1016/S0065-2156(07)41002-X

[88] McClellan, P., Landis, W.J. (2016). Recent applications of coaxial and emulsion electrospinning methods in the field of tissue engineering. BioResearch open access, 5(1): 212-227. https://doi.org/10.1089/biores.2016.0022

[89] Deitzel, J.M., Kosik, W., McKnight, S.H., Tan, N.B., DeSimone, J.M., Crette, S. (2002). Electrospinning of polymer nanofibers with specific surface chemistry. Polymer, 43(3): 1025-1029. https://doi.org/10.1016/S0032-3861(01)00594-8

[90] Morozov, V., Morozova, T., Kallenbach, N. (1998). Atomic force microscopy of structures produced by electrospraying polymer solutions. International Journal of Mass Spectrometry, 178(3): 143-159. https://doi.org/10.1016/S1387-3806(98)14083-6

[91] Chang J.S., Kelly A.J., Crowley J.M. (1995). Handbook of Electrostatic Processes. Journal of Cleaner Production, 3(3): 175. https://doi.org/10.1016/0959-6526(95)900012

[92] Shao, C., Kim, H.Y., Gong, J., Ding, B., Lee, D.R., Park, S.J. (2003). Fiber mats of poly (vinyl alcohol)/silica composite via electrospinning. Materials Letters, 57(910): 1579-1584. https://doi.org/10.1016/S0167577X(02)01036-4

[93] Peresin, M.S., Habibi, Y., Zoppe, J.O., Pawlak, J.J., Rojas, O.J. (2010). Nanofiber composites of polyvinyl alcohol and cellulose nanocrystals: Manufacture and characterization. Biomacromolecules, 11(3): 674-681. https://doi.org/10.1021/bm901254n

[94] Kenawy, E.R., Abdel-Fattah, Y.R. (2002). Antimicrobial properties of modified and electrospun poly (vinyl phenol). Macromolecular Bioscience, 2(6): 261-266. https://doi.org/10.1002/16165195(200208)2:6<261::AID-MABI261>3.0.CO;2-2

[95] Agarwal, S., Wendorff, J.H., Greiner, A. (2008). Use of electrospinning technique for biomedical applications. Polymer, 49(26): 5603-5621. https://doi.org/10.1016/j.polymer.2008.09.014

[96] Russo, G., Lamberti, G. (2011). Electrospinning of drugloaded polymer systems: Preparation and drug release. Journal of applied polymer science, 122(6): 3551-3556. https://doi.org/10.1002/app.34764

[97] Lin, Q., Li, Y., Yang, M. (2012). Polyaniline nanofiber humidity sensor prepared by electrospinning. Sensors and Actuators B: Chemical, 161(1): 967-972. https://doi.org/10.1016/j.snb.2011.11.074
[98] Landau, O., Rothschild, A., Zussman, E. (2009). Processing-microstructure-properties correlation of ultrasensitive gas sensors produced by electrospinning. Chemistry of Materials, 21(1): 9-11. https://doi.org/10.1021/cm802498c

[99] Camerlo, A., Vebert-Nardin, C., Rossi, R.M., Popa, A.M. (2013). Fragrance encapsulation in polymeric matrices by emulsion electrospinning. European polymer journal, 49(12): 3806-3813. https://doi.org/10.1016/j.eurpolymj.2013.08.028

[100] Demir, M.M., Yilgor, I., Yilgor, E.E.A., Erman, B. (2002). Electrospinning of polyurethane fibers. Polymer, 43(11): 3303-3309. https://doi.org/10.1016/S00323861(02)00136-2

[101] Megelski, S., Stephens, J.S., Chase, D.B., Rabolt, J.F. (2002). Micro-and nanostructured surface morphology on electrospun polymer fibers. Macromolecules, 35(22): 8456-8466. https://doi.org/10.1021/ma020444a

[102] Costa, L.M.M., Bretas, R.E.S., Gregorio, R. (2010). Effect of solution concentration on the electrospray/electrospinning transition and on the crystalline phase of PVDF. Mater. Sci. Appl, 1(4): 246251. https://doi.org/10.4236/msa.2010.14036

[103] Erokhina, O.V., Artemov, A.V., Gal'Braikh, L.S., Vikhoreva, G.A., Polyutov, A.A. (2006). State of lithium cation in a solution of polyurethane in deviethylformamide. Fibre Chemistry, 38(6): 447-449. https://doi.org/10.1007/s10692-006-0107-z

[104] Audrey Frenot, IoannisS. Chronakis., (2003). Polymer nanofibers assembled by electrospinning. Current Opinion in Colloid and Interface Science, 8(0): 64-75. https://doi.org/10.1016/S1359-0294(03)00004-9

[105] Kataphinan, W., Dabney, S., Smith, D., Reneker, D. (2001). Fabrication of electrospun and encapsulation into polymer nanofibers. In Book of Abstracts. The Fiber Society, Spring Meeting.

[106] Matthews, J.A., Wnek, G.E., Simpson, D.G., Bowlin, G.L. (2002). Electrospinning of collagen nanofibers. Biomacromolecules, $3(2)$ : 232-238. https://doi.org/10.1021/bm015533u

[107] Buchko, C.J., Chen, L.C., Shen, Y., Martin, D.C. (1999). Processing and microstructural characterization of porous biocompatible protein polymer thin films. Polymer, 40(26): 7397-7407. https://doi.org/10.1016/S0032-3861(98)00866-0

[108] Buchko, C.J., Slattery, M.J., Kozloff, K.M., Martin, D.C. (2000). Mechanical properties of biocompatible protein polymer thin films. Journal of Materials Research, 15(1): 231-242. https://doi.org/10.1557/JMR.2000.0038

[109] Buchko, C.J., Kozloff, K.M., Martin, D.C. (2001). Surface characterization of porous, biocompatible protein polymer thin films. Biomaterials, 22(11): 12891300. https://doi.org/10.1016/S0142-9612(00)00281-7

[110] Hohman, M.M., Shin, M., Rutledge, G., Brenner, M.P. (2001). Electrospinning and electrically forced jets. II. Applications. Physics of fluids, 13(8): 2221-2236. https://doi.org/10.1063/1.1384013

[111] Jin, H.J., Fridrikh, S.V., Rutledge, G.C., Kaplan, D.L. (2002). Electrospinning Bombyx mori silk with poly (ethylene oxide). Biomacromolecules, 3(6): 1233-1239. https://doi.org/10.1021/bm025581u

[112] Chuangchote, S., Supaphol, P. (2006). Fabrication of aligned poly (vinyl alcohol) nanofibers by 
electrospinning. Journal of nanoscience and nanotechnology, 6(1): 125-129. https://doi.org/10.1166/jnn.2006.17916

[113] Deitzel, J.M., Kleinmeyer, J., Harris, D.E.A., Tan, N.B. (2001). The effect of processing variables on the morphology of electrospun nanofibers and textiles. Polymer, 42(1): 261-272. https://doi.org/10.1016/S00323861(00)00250-0

[114] De Vrieze, S., Van Camp, T., Nelvig, A., Hagström, B., Westbroek, P., De Clerck, K. (2009). The effect of temperature and humidity on electrospinning. Journal of materials science, 44(5): 1357-1362. https://doi.org/10.1007/s10853-008-3010-6

[115] Deng, L., Young, R.J., Kinloch, I.A., Zhu, Y., Eichhorn, S.J. (2013). Carbon nanofibres produced from electrospun cellulose nanofibres. Carbon, 58: 66-75. https://doi.org/10.1016/j.carbon.2013.02.032

[116] Gibson, P.W., Schreuder-Gibson, H.L., Rivin, D. (1999). Electrospun fiber mats: transport properties. AIChE journal, 45(1): 190-195. https://doi.org/10.1002/aic.690450116

[117] Smith D., Reneker DH. (2001). PCT/US00/27737
[118] Shao, C., Kim, H.Y., Gong, J., Ding, B., Lee, D.R., Park, S.J. (2003). Fiber mats of poly (vinyl alcohol)/silica composite via electrospinning. Materials Letters, 57(910): $\quad 1579-1584$. https://doi.org/10.1016/S0167$577 \mathrm{X}(02) 01036-4$

[119] Joly, D., Jung, J.W., Kim, I.D., Demadrille, R. (2016). Electrospun materials for solar energy conversion: innovations and trends. Journal of Materials Chemistry $\quad$ C, 4(43): $10173-10197$. https://doi.org/10.1039/C6TC00702C

[120] Ali, K., Raza, H.A., Malik, M.I., Ibn Shamsah, S., Amna, R., Sarfraz, A. (2020). To Study the Effect of LiMn2O4, Nanofibers of LiMn2O4, and Graphene/Polyaniline/Carbon Nanotube as Electrode Materials in the Fuel Cell. Journal of New Materials for Electrochemical Systems, 23(1): 1-6. https://doi.org/10.14447/jnmes.v23i1.a07

[121] Sun, G., Sun, L., Xie, H., Liu, J. (2016). Electrospinning of nanofibers for energy applications. Nanomaterials, $6(7)$ : https://doi.org/10.3390/nano6070129 